\title{
A DIMENSÃO DA AÇÃO NAS REPRESENTAÇÕES SOCIAIS DA TECNOLOGIA NO CUIDADO DE ENFERMAGEM ${ }^{\mathrm{a}}$
}

\author{
The dimension of the action in the social representations of the technology in the care \\ of nursing \\ La dimensión de la acción en las representaciones sociales de la tecnología en el cuidado \\ del oficio de enfermera
}

Rafael Celestino da Silva ${ }^{1}$

Márcia de Assunção Ferreira²

\begin{abstract}
RESUMO
Objetiva-se identificar os modos de agir dos enfermeiros diante do cuidado do cliente portador de aparatos tecnológicos, a partir de suas representações sociais sobre a tecnologia. 0 referencial teórico foi o da teoria das representações sociais. Pesquisa qualitativa, com realização de entrevistas, observação sistemática e análise de conteúdo temática. Sujeitos: onze enfermeiros novatos e treze veteranos. Os resultados mostraram a existência de duas linhas condutoras da ação do enfermeiro junto ao cliente que se utiliza dos aparatos tecnológicos: a do cuidado tecnológico, no qual existe uma ação que articula o saber tecnológico e os saberes inerentes ao cuidado de enfermagem; e a da ação tecnológica, em que o profissional age orientado somente tendo em vista a máquina. Concluiu-se que a tecnologia pode estar orientando a formação de determinados estilos de cuidar na enfermagem.
\end{abstract}

Palavras-chave: Tecnologia Biomédica. Unidades de Terapia Intensiva. Enfermagem. Cuidados de Enfermagem. Psicologia Social

\begin{abstract}
It aims to identify the nurses' ways of acting when taking care of customer carrying technological devices, from its social representations on the technology. It was used as a reference the theory of the social representations. It's a qualitative research, with the accomplishment of interviews, systematic comment and thematic analysis of the content. Subjects: eleven inexperienced nurses and thirteen veterans. The results showed the existence of two conducting lines of the nurse action regarding the customer that uses the technological devices: the technological care, which there is an action that manages the technological and the inherent knowledge to the care of nursing; and the technological action, where the professional acts only guided by the machine. It is concluded that the technology may be directing the formation of certain care styles in the nursing.
\end{abstract}

Keywords: Biomedical technology. Intensive Care Units. Nursing. Nursing Care. Psychology Social

\section{Resumen}

Se objetiva identificar las maneras de actuar de los enfermeros frente al cuidado del cliente portador de aparatos tecnológicos, a partir de sus representaciones sociales sobre la tecnología. El referencial teórico fue la teoría de las representaciones sociales. Investigación cualitativa, con realización de entrevistas, observación sistemática y análisis de contenido temático. Sujetos: once enfermeros novatos y trece veteranos. Los resultados mostraron la existencia de dos líneas conductoras de la acción del enfermero junto al cliente que se utiliza de los aparatos tecnológicos: la del cuidado tecnológico, en el cual existe una acción que articula el saber tecnológico y los saberes inherentes al cuidado de enfermería; y la de la acción tecnológica, en que el profesional actúa orientado solamente teniendo en cuenta la máquina. Se concluye que la tecnología puede estar orientando la formación de determinados estilos de cuidar en la enfermería.

Palabras clave: Tecnología biomédica. Unidades de Terapia Intensiva. Enfermería. Cuidados de Enfermería. Psicología social

\footnotetext{
${ }^{1}$ Mestre em Enfermagem. Professor do Curso de Graduação em Enfermagem da Universidade Castelo Branco. Aluno do Curso de Doutorado da Escola de Enfermagem Anna Nery. Membro do Núcleo de Pesquisa de Fundamentos do Cuidado de Enfermagem. Rio de Janeiro, RJ. Brasil. E-mail: rafaenfer@yahoo.com.br, ${ }^{2}$ Doutora em Enfermagem. Professora Titular do Departamento de Enfermagem Fundamental da Escola de Enfermagem Anna Nery, Universidade Federal do Rio de Janeiro. Coordenadora Geral de Pós-graduação e Pesquisa. Membro do Núcleo de Pesquisa de Fundamentos do Cuidado de Enfermagem. Rio de Janeiro, RJ. Brasil.E-mail:marciadeaf@ibest.com.br
} 


\section{INTRODUÇÃO}

No estudo das representações sociais dos enfermeiros de uma Unidade Cardiointensiva sobre a tecnologia inserida neste cenário, ${ }^{1}$ foi possível perceber que existe uma concepção sobre o ambiente do Centro de Terapia Intensiva (CTI) que o aproxima da morte. Tal concepção está intimamente relacionada ao fato de que neste ambiente há muitos aparatos tecnológicos. Estes aparatos representam a gravidade do cliente, isto é, quanto mais aparato, mais grave o cliente está. Quanto mais grave está, mais próximo da morte se encontra. Neste sentido, a presença da tecnologia no ambiente indica maior proximidade do cliente à morte. A tecnologia no $\mathrm{CTI}$ pressupõe um determinado estado para o cliente.

À luz deste entendimento, considera-se que existe uma representação social sobre o ambiente de terapia intensiva que o vincula a uma noção de terminalidade, finitude, sofrimento e gravidade. Esta representação orienta o modo como os enfermeiros estruturam o pensamento sobre a tecnologia. As ideias pré-concebidas sobre o ambiente do CTI, formadas com base na circulação de informações, seja nas rodas de conversa ou a partir do acesso aos meios de comunicação em massa, fazem com que o enfermeiro, ao entrar em contato com este cenário, marcado pela presença de aparatos tecnológicos extremamente avançados, os quais exercem funções de suporte, substituição da função de órgãos e manutenção da vida, articule tal imaginário ao uso da tecnologia no cliente. ${ }^{1}$

Assim, o uso das tecnologias no cliente, pelo fato de exercerem poder sobre a vida, denotam um retrato de gravidade e provável morte. Por sua vez, tal representação construída sobre ela for talece ainda mais o sentido que é atribuído ao ambiente, de modo que ambas passam a estar implicadas, retroalimentando-se mutuamente.

Para assistir a um cliente sob uso de aparatos tecnológicos, que se pressupõe estar em estado grave, à morte, é necessário que o enfermeiro tenha conhecimento teóricoprático tanto inerente à profissão, ou seja, aos saberes relativos aos cuidados de enfermagem, quanto no que se refere especificamente ao manuseio das máquinas. Esta compreensão se ampara na concepção de que o cuidado de enfermagem comporta na sua estrutura um conhecimento científico que é fruto de um preparo teórico-filosófico e técnico formal, assim como no entendimento da tecnologia como resultado objetivo da ciência.

Desta maneira, o não domínio deste conhecimento teórico-prático - da profissão e das máquinas - pelo enfermeiro pode levar o cliente à morte, o que se configura em uma situação difícil para o profissional lidar: o fato de ser responsabilizado pela morte do cliente em virtude do manuseio incorreto ou não manuseio do maquinário tecnológico, inclusive em termos de implicações éticas. Também, a lógica que orienta a prática destes profissionais é a de que o impacto da morte dos clientes representa o insucesso de todos os esforços e investimentos realizados pela equipe multiprofissional no período em que este ficou internado. ${ }^{2}$

Contudo, há de se considerar, nesta discussão, que no processo de alocação e distribuição dos enfermeiros no hospital seus conhecimentos, experiências e preferências nem sempre são consideradas. Este fator faz com que muitos profissionais sem experiências - novatos ${ }^{3}$ - sejam admitidos em setores de cuidados intensivos. Os enfermeiros sem experiência são aqueles que não dominam as ferramentas necessárias ao cuidado da clientela de um determinado cenário.

Tais enfermeiros novatos caracterizam-se por ter um comportamento que, via de regra, é limitado e inflexível. ${ }^{3}$ Suas restrições de atuação tornam-se ainda mais evidentes quando se pensa nas tecnologias incorporadas ao cuidado, visto que estas demandam conhecimentos e habilidades dos profissionais, no sentido de funcionarem como instrumental complementar.

Conjectura-se que a inexperiência na prática de cuidar possa produzir um negligenciamento de determinadas ações aos clientes em uso de aparatos tecnológicos, bem como produzir um grau de afastamento. Desta feita, a pergunta que se coloca é a seguinte: diante das representações sociais da tecnologia, formadas a partir da ideia de gravidade e risco de morte do cliente, e considerando as características dos profissionais atuantes neste cenário em relação ao tempo de experiência, como os enfermeiros se comportam diante do cuidado do cliente internado em setores tecnológicos? Sendo assim, objetiva-se identificar os modos de agir dos enfermeiros perante o cuidado do cliente portador de aparatos tecnológicos, a partir de suas representações sociais sobre a tecnologia.

\section{REFERENCIAL TEÓRICO E METODOLÓGICO}

Estudo descritivo, qualitativo, com aplicação da vertente processual da teoria das representações sociais (TRS). As representações sociais (RS) são uma forma de conhecimento prático, que estabelece os nexos entre o pensamento e as ações dos sujeitos, ajudando-os a se orientarem no mundo. ${ }^{4} \mathrm{Os}$ objetos de RS são socialmente relevantes e fazem parte das discussões e conversas cotidianas dos sujeitos sociais. A tecnologia, principalmente a que integra o universo da terapia intensiva, importa para os enfermeiros, mormente para aqueles que lidam com ela no cotidiano de suas práticas. Há um imaginário sobre as tecnologias usadas na terapia intensiva. Consideradas complexas, admiradas e/ou temidas, a tecnologia de terapia intensiva se configura em objeto de RS para o grupo de enfermeiros, justificando a aplicação da TRS na abordagem deste objeto, uma vez que a representação social expressa um "modo de pensamento sempre ligado à ação, à conduta individual e coletiva," ${ }^{55}$ "59 adquirindo, portanto, o social.

0 cenário foi a Unidade Cardiointensiva de um hospital federal de grande porte do município do Rio de Janeiro. 0 universo da pesquisa constou de 30 enfermeiros. Com a 
aplicação dos critérios de inclusão, participaram 24 enfermeiros dos períodos diurnos e noturnos. Dos 6 restantes, 4 estavam de férias, licença, e 2 recusaram-se a participar da pesquisa. Os participantes foram classificados em dois grandes grupos: novatos - aqueles com atuação profissional de até 2 anos em setores altamente tecnológicos; e veteranos - aqueles com atuação profissional superior a 2 anos em setores altamente tecnológicos.

Realizou-se entrevista individual, com roteiro de questões semiestruturadas, e 40 horas de observação sistemática da prática dos enfermeiros. Para o registro da observação, aplicou-se a descrição densa; e ao conteúdo das entrevistas, as técnicas de análise temática de conteúdo na busca de unidades de registro e de contexto que configurassem as categorias empíricas. Os conteúdos foram organizados em temas que se agregaram em torno de categorias sobre os modos de agir dos enfermeiros e tipificaram tais modos como "cuidado tecnológico" e "ação tecnológica".

0 anonimato dos sujeitos foi garantido com a identificação por códigos alfanuméricos: $\mathrm{E}$ : enfermeiro; $\mathrm{N}$ : novato; V: veterano; F: feminino; M: masculino, N: turno de trabalho noturno; D: turno de trabalho diurno; e o número correspondente à ordem sequencial das entrevistas. 0 projeto foi aprovado pelo Comitê de Ética em Pesquisa do Hospital dos Servidores do Estado-RJ, protocolo n 000.298 , e todos os participantes assinaram o Termo de Consentimento Livre e Esclarecido. A coleta de dados ocorreu no período de dezembro de 2007 a março de 2008

\section{RESULTADO E DISCUSSÃO}

Neste estudo, a análise de conteúdo aplicada aos dados empíricos levou-nos a entender que os sujeitos tipificam o cuidado, existindo certo tipo de cuidado específico que é realizado no ambiente de terapia intensiva, na dependência da utilização da tecnologia no cliente, e outra forma diferenciada de cuidar dirigida aos clientes que dela não necessitam e que, geralmente, estão em outros setores do hospital.

Este cuidado diferenciado foi ressaltado por dois terços dos entrevistados (16). Tal diferença se ampara na questão do conhecimento do enfermeiro e no grau de atenção dispensado ao cliente. A ocorrência dos elementos diferenciadores do cuidado foi identificada da seguinte forma: 'grau de atenção' em 8 depoimentos, 'conhecimento' em 5, bem como a coocorrência da 'atenção' com o 'conhecimento' em 3 depoimentos. Os enfermeiros se referem, então, ao tipo de cuidado que é realizado aos clientes que precisam de tecnologia como especial e diferenciado:

O cuidado você vai ter em relação a todos os pacientes, mas com relação à tecnologia que você aplique ao doente, que o paciente exige naquele determinado momento, isso leva o enfermeiro a ter um cuidado diferenciado. (EVFD8)

Eu não posso afirmar categoricamente que eles são melhores, agora que eles (...) precisam de um cuidado diferenciado, sem dúvida nenhuma. Eu diria que eles necessitam, sim, de uma atenção especial, de um cuidado diferenciado. (EVMN13)

Os cuidados de enfermagem prestados na terapia intensiva são marcados por um superlativo, evidenciado nos discursos pela utilização do advérbio mais. Neste sentido, 0 cuidado ganha um status diferenciado, uma vez que neste ambiente exige-se mais, em termos de qualidade e quantidade, seja na qualificação profissional seja na prática em si dos cuidados intensivos. Neste superlativo sobressaíram-se maior atenção/observação, mais conhecimento, mais agilidade, mais trabalho. ${ }^{6}$

Na pesquisa em tela, uma das características que qualificam este cuidado como diferenciado é o gradiente de aplicação do conhecimento. 0 que diferencia o cuidado do cliente que precisa de tecnologia para aquele que não precisa é o grau de conhecimento que o enfermeiro aplica para cuidar desses clientes. 0 cliente que depende de tecnologia precisa de maior aporte de conhecimentos, que possibilite ao enfermeiro não somente manusear as aparelhagens, mas também interpretar as informações fornecidas por estas, associando-as ao conjunto de sinais e sintomas que o cliente apresenta.

O que diferencia mesmo é o conhecimento que a gente tenha a respeito da tecnologia que esteja implicada naquele paciente. (ENFN14)

(...) por isso que é diferenciado e mais difícil (...) só em um você tem que incluir mais, um conhecimento mais teórico, uma coisa mais específica do equipamento que é usado em um e de outro não. (EVFD6)

Acaba tendo que ter um conhecimento maior para estar atendendo adequadamente, porque são inúmeros os detalhes que essa tecnologia exige que o enfermeiro saiba. Alarmes e mais alarmes, sinais e mais sinais, monitores, ventiladores artificiais, etc. Toda essa parafernália, ela exige um conhecimento um pouco mais detalhado desse equipamento, para que você possa estar atendendo o paciente adequadamente. (EVMD19)

Destaca-se a necessidade de utilização pelo enfermeiro de maior conhecimento científico, tanto no que compete ao cuidado em si quanto no que se refere ao funcionamento dos 
equipamentos tecnológicos presentes no CTI. Deste modo, para se atuar no CTl é preciso dominar os elementos que compõem o cabedal de conhecimentos específicos do cuidar e dos cuidados de enfermagem, assim como aprofundar os saberes que propiciem empregar, de forma eficiente e eficaz, os aparatos tecnológicos. ${ }^{6}$

\section{0 cuidado tecnológico}

0 processo de elaboração das representações sociais envolve classificar e denominar. Coisas que não são classificadas nem denominadas são estranhas, não existentes e ao mesmo tempo ameaçadoras. Deste modo, argumenta-se que os objetos devem ter valores positivos ou negativos, ocupando uma determinada posição numa hierarquia, não admitindo, portanto, uma neutralidade. ${ }^{?}$

As representações sociais são categorias que servem para classificar as circunstâncias, fenômenos, pessoas com as quais nós temos contato, permitem definir o status. São, por fim, um instrumento para compreender o outro, nos conduzindo diante dele e the atribuindo um lugar social. ${ }^{4}$ Se as representações sociais ajudam a classificar e a por ordem nas coisas, ajudam também a definir as prioridades, e as ações. Por isso, o gradiente é importante de ser detectado, pois nos ajuda a entender 0 porquê das ações, qual a lógica que sustenta as escolhas, por que o cliente que usa a tecnologia precisa de um cuidado diferenciado, superlativizado, em relação àquele que não a utiliza.

Ainda no que tange à questão do conhecimento, enquanto um dos aspectos que sustentam o discurso da tipologização do cuidado, é importante destacar a necessidade de intermediação de uma série de conhecimentos para cuidar do cliente que depende de tecnologia. Portanto, éfundamental que o enfermeiro seja capaz de deter um conhecimento em relação às máquinas (manuseio/domínio), aos aspectos fisiopatológicos da doença em curso, assim como um conhecimento semiológico que 0 possibilite estabelecer as interfaces entre os sinais e sintomas referidos ou apresentados, com as informações provenientes da máquina e as manifestações clínicas da doença, aliando-os aos elementos fundamentais do cuidado de enfermagem, que incluem o toque, a audição, a observação. Ao reunir tais habilidades ele consegue realizar esse cuidado dito especial.

Você tem que ter o conhecimento da patologia, conhecimento prático, conhecimento também da assistência que você está prestando ao paciente e saber também que não é só olhar para o monitor, você também tem que levar em consideração o que o paciente sente, né?. (EVFD5)

É claro que para um cliente que demanda, usa tecnologia, você precisa estar adequando, além dos conhecimentos do cuidado de enfermagem, os seus conhecimentos da tecnologia que você usa junto.
Então, você tem que somar os dois conhecimentos: tanto do cuidado essencial quanto da tecnologia. (EVFD6)

0 enfermeiro que trabalha em um setor de tecnologia de ponta tem que ter muito conhecimento, tanto da parte dos equipamentos, mas também a parte do diagnóstico, a parte da fisiopatologia da doença e também dos cuidados que você vai prestar ao cliente. (EVFD5)

O saber interpretar a máquina (...) você tem que saber interpretar os dados da máquina e olhar para o cliente. Os dados, muitas das vezes, não te dão nada, mas olhar para o cliente, você tocar o cliente, sim, unindo as duas coisas você observa, sente muita coisa. (EVFN12)

0 mal uso dos recursos tecnológicos pode colocar a vida do cliente em risco. Assim, reitera-se a importância de que se atente também para a máquina, com o propósito final de manter a vida dos clientes. Esta atenção envolve conhecimentos técnicos e racionais que possibilitem fundamentar as ações perante as tecnologias. ${ }^{8}$

A cada dia é aprimorada a capacidade da equipe em observar o cliente. A observação atenta das máquinas, através das informações e sinais que ela dá, ajuda a equipe de enfermagem a conhecer melhor o que se está passando no organismo do cliente e, assim, direcionar o seu cuidado. Para que não haja erros na tradução das informaç̃̃es advindas das máquinas, o corpo do enfermeiro precisa estar interagindo com elas, sendo, portanto, fundamental, múltiplas aprendizagens. ${ }^{9}$

Muito embora as máquinas se expressem através de valores objetivos, os mesmos precisam ser complementados com aqueles referentes à subjetividade humana, denotando a importância do profissional no sentido de interpretar tais informações. ${ }^{10}$ Sob este aspecto, a utilização de aparatos tecnológicos que facilitam a assistência ao cliente crítico e que requerem vários cuidados, sejam de ajuste, manutenção, calibração, os quais exigem atenção e zelo dos profissionais para garantir a fidedignidade dos dados, não deve invalidar uma compreensão acerca dos cuidados de enfermagem, considerando o uso de tecnologias como uma ação humana. ${ }^{8}$

Há expressões de cuidado humano, ${ }^{11}$ mesmo em um setor repleto de tecnologias. 0 fato de o enfermeiro em determinados momentos atribuir maior atenção à máquina, não significa necessariamente falta de dedicação ou atenção ao cliente, mas pode refletir uma preocupação com seu bemestar e manutenção de suas funções vitais. Apesar de haver a necessidade de habilidade e destrezas para manejar os aparatos, isso não significa dizer que o foco de atenção é somente a máquina, relegando o cliente, sujeito do cuidado, a segundo plano. ${ }^{6}$ 
Outra diferença é o nível de atenção exigido do enfermeiro para o cuidado dos clientes sob uso de tecnologia, pois estes requerem maior atenção e um olhar mais atento no acompanhamento de sua evolução clínica. Assim, é importante que o enfermeiro esteja a todo o tempo direcionando sua avaliação a eles, no intuito de identificar possíveis demandas que requeiram cuidados de enfermagem para serem atendidas, uma vez que o grau de dependência deles também é maior.

Os que estão necessitando de mais tecnologia, geralmente são pacientes mais graves que requerem um pouco mais de atenção, e o paciente que não está usando nenhuma tecnologia normalmente é um paciente que está um pouco menos grave, depende do quadro clínico. Então, não requer que você fique ali o tempo todo do lado dele. Então, a diferença é basicamente essa: é o grau de atenção que você tem que dar para um e para outro, porque um paciente com recurso tecnológico você acaba tendo que ficar sua atenção o tempo todo voltada para ele. (EVFD4)

Jáo paciente que está precisando de uma tecnologia, para mim, é um paciente que está requerendo um pouco mais de atenção, por algum motivo (...) mas normalmente, falando de uma média, a maioria deles precisam de uma atenção maior. (ENFN18)

0 cuidado prestado ao cliente internado no CTI deve ser executado tomando como referência os problemas fisiopatológicos e questões psicossociais, ambientais e familiares, uma vez que tais aspectos se articulam com a doença física. Nesta perspectiva, a essência da assistência de enfermagem no âmbito dos cuidados intensivos está centrada no processo de tomada de decisões, o qual, por conseguinte, deve basear-se nas condições fisiológicas e psicológicas do cliente. $^{12}$

0 cuidado de enfermagem se expressa no conhecimento e sua aplicação prática no domínio das máquinas, mas também abarca elementos do cuidado humano, ${ }^{11}$ uma vez que representa toda a expressividade de cuidar neste momento de encontro, intermediado pelas máquinas.

A partir dos elementos tipificadores deste cuidado, 0 mesmo foi denominado nesta pesquisa como cuidado tecnológico, na medida em que se estabelece como uma resposta à forma como os elementos que compõem a noção sobre a tecnologia são manifestados na prática. Trata-se, portanto, de um cuidado diferenciado, marcado pela aplicação de um maior conhecimento pelo enfermeiro, o qual orienta sua atenção na busca de dados objetivos e subjetivos oriundos do cliente, bem como objetivos provenientes do maquinário. Assim, este cuidado tecnológico se efetiva a partir da representação que os enfermeiros constroem sobre a tecnologia, que neste caso associa o seu uso à gravidade do cliente e proximidade da morte, o que produz a necessidade de uma prática marcada sempre por um superlativo, evidenciado pelo uso do advérbio mais, voltada a reverter este quadro em que há um risco iminente de morte do cliente.

Á emergência de elementos tipificadores do cuidado tecnológico após a aplicação das técnicas de análise de conteúdo aos depoimentos dos sujeitos permite refletir sobre o debate acerca do conceito de tecnologia. Uma vez que os entrevistados referem que, para cuidar do cliente que se utiliza das tecnologias, é necessário unir saberes acerca do manuseio do maquinário, da fisiopatologia da doença, da semiologia, dos elementos fundamentais do cuidado e da interpretação dos dados oriundos do uso das aparelhagens, evidencia-se que a tecnologia comporta em si um saber, enquanto fruto de uma produção da ciência, o qual precisa ser articulado a uma série de outros conhecimentos para que se alcance o seu uso apropriado no cuidado do cliente.

Desta maneira, entende-se que a tecnologia envolve um saber em potencial, e, a partir do encontro desta tecnologia com o profissional que a manuseia, com os seus conhecimentos acumulados, é que o saber tecnológico ganha dinamicidade, e tal tecnologia pode ser aplicada na assistência ao cliente. Logo, é a figura humana que viabiliza a aplicação do saber em potência que a tecnologia traz.

Alguns elementos que constituem o cuidado tecnológico puderam ser visualizados no cotidiano de cuidar dos enfermeiros através da observação sistemática de suas práticas. Nesta, identificou-se que os enfermeiros, na prestação de cuidados aos clientes que se utilizam dos aparatos tecnológicos, buscam estabelecer um processo de interação que dê conta de identificar as necessidades vivenciadas por eles. Essas necessidades são não somente de ordem física, mas também demandas advindas a partir dos sentimentos originados da experiência do processo de hospitalização, o que denota um entendimento de que o cuidado deve ser de perspectiva integradora.

\section{A ação tecnológica}

Em contraponto ao que se convencionou chamar de cuidado tecnológico, tem-se a ação tecnológica, configurada a partir de elementos destacados por dez dos entrevistados. Este tipo de ação está articulado ao uso da tecnologia no cuidado, com destaque para a supremacia da máquina, o que foi qualificado como um malefício. Nesta ação, o direcionamento do cuidado ocorre somente pelas informações provenientes do aparato tecnológico, deixando-se de observar os dados fornecidos pelo olhar dirigido ao cliente, resultando em última instância num olhar cego. Tal ação se situa numa zona tênue na qual estão os cuidados instrumentais (técnicos) e expressivos, ${ }^{13}$ em limites e fronteiras que devem ser debatidos quando se propõe dialogar acerca da inserção de tecnologias no ambiente do cuidado. 
Na ação tecnológica, os profissionais se deixam conduzir somente pela máquina, não existindo uma interlocução entre o olhar voltado ao cliente e aquele cujo foco é a aparelhagem. Pode então trazer consequências danosas ao cliente, uma vez que a máquina também falha, e, neste sentido, pode vir a trazer malefícios. Além disso, o cuidar instruído somente pela tecnologia não responde pela totalidade de demandas do indivíduo, não sendo, portanto, integral.

A atenção dirigida ao cliente, buscando identificar possíveis necessidades originadas da vivência de sentimentos como medo da morte, susto, estranhamento, que podem por sua vez interferir no seu estado de doença, já que abarcam subjetividades que não podem ser identificadas pela máquina, é negligenciada. Desta maneira, o cuidado não leva em consideração tais demandas.

(...) muitas vezes, o que eu percebo até em mim mesmo, ou então nas outras pessoas, éque às vezes, a gente passa a prestar atenção mais na máquina do que no paciente, você está tão acostumada em ver os parâmetros que a máquina te dá, está tão acostumado a ver o que ela vai te mostrar daquele paciente, que muitas vezes você deixa de olhar para o paciente, para ver a clínica dele, os sintomas que ele está apresentando, você vai se prender naquilo que a máquina está te dando. (ENFD1)

Tem seu lado positivo e negativo e também tem gente que dá valor só a tecnologia, às vezes nem olha para a cara do doente. Tem uma conhecida minha que ficou no CTI e ela falou que todo mundo chegava no leito dela e não olhava para a cara dela, só olhava para o monitor, como se ela não existisse ali, era só o monitor. Então tem esse lado negativo, você esquece de ir lá examinar o paciente, levantar o lençol e ver como ele está, conversar com ele. Vira só um valor na tela. (EVFD9)

Uma assistência prestada somente a partir das informações geradas mediante ao manuseio das máquinas produz um distanciamento do cliente, o qual não consegue comunicar todas as suas necessidades ao enfermeiro, e este, por sua vez, não 0 atende integralmente, resultando em uma ação que não se configura como cuidado.

0 equipamento veio para te ajudar, e não para te atrapalhar, só que muitas vezes você confia muito no equipamento, espera o monitor apitar para você ir lá atender o paciente. Você esquece muitas vezes de olhar o paciente, você tem um olhar crítico sobre a patologia do paciente e você olha só os parâmetros do respirador, e não vê o paciente como um todo. Às vezes o paciente está lá saturando, sei lá 85, e lá na marcação não está uma boa curva, você não interpretou bem a curva e está 99, o paciente está lá na sua frente e você não olha o paciente, você olha os equipamentos. (EVFD7)

Quanto mais recursos se investem parece que a atenção ao ser humano tem ficado pior, as pessoas ficam mais dependentes de equipamentos, em contrapartida a equipe vai se afastando mais, vai dando menos atenção ao ser humano, só fica atenta aos equipamentos. (EVFD4)

Esta característica de atuação nos ambientes tecnológicos, no qual o enfermeiro deve aliar elementos instrumentais e expressivos, ${ }^{13}$ aparenta ser um elemento da zona muda das representações sociais. ${ }^{14}$ Tal afirmação se ampara no fato de que os enfermeiros geralmente falam sobre os outros e não de si próprios. Ao conversarem sobre o cuidado prestado em ambientes tecnológicos, os enfermeiros quando falam das situações em que o cuidado é direcionado apenas pelas informações oriundas do maquinário, esquecendo-se de olhar para o cliente na busca de suas necessidades, nunca se referem a si mesmos, mas sempre falam de outros colegas.

Isso pode ser explicado pela identidade do conhecimento do enfermeiro sobre o cuidado ser instruído por um discurso fortemente humanista, no qual o cliente seria o centro das atenções e o que direcionaria o cuidado. No entanto, se no ambiente tecnológico a máquina e o saber/ ciência que ela expressa tem supremacia sobre o saber/ciência da enfermagem, e isto define/determina a ação do enfermeiro - a ação tecnológica -, ele, o enfermeiro, se exclui desta discussão e fala dos outros, e não dele próprio.

Esta zona muda constitui-se de uma segunda parte da representação, composta de elementos que não são verbalizáveis, não são expressos pelos sujeitos entrevistados. A zona muda é composta de elementos da representação que são contranormativos, ou seja, cognições ou crenças que não são expressas pelo sujeito em condições normais de produção, pois podem entrar em conflito com valores morais ou normas de um determinado grupo. ${ }^{14}$

A existência da ação tecnológica pode ser evidenciada também através dos dados reunidos através da observação sistemática, os quais mostraram que no atendimento das demandas relativas, sejam do cliente em si, sejam do próprio maquinário, o profissional direciona o olhar diretamente para o aparato tecnológico e esquece que algumas vezes o problema identificado pode ser solucionado a partir de uma maior atenção ao sujeito que se encontra sob os seus cuidados.

Foi possível detectar com melhor clareza nos depoimentos dos veteranos uma preocupação maior com a valorização dos aspectos humanos no cuidado ao cliente. Neste sentido, à medida que o tempo de experiência profissional nesta área avança, o enfermeiro começa a se interrogar quanto 
à sua estada naquele ambiente, bem como sobre a importância que é dada à máquina em relação ao sujeito do cuidado, que é o cliente, e sobre as relações que são estabelecidas no campo do cuidado. Enfim, inicia um processo de reflexão acerca da prática de cuidado do enfermeiro em unidades tecnológicas, que pode levar a adquirir uma nova percepção sobre o cuidado aos clientes que dependem de tecnologia.

Na época de residência eu me via como um enfermeiro high tech, porque eu estava sempre estudando, gostava de terapia intensiva. (pausa) Uma questão efetivamente de identificação. Várias coisas. Situações pessoais mesmo, em relação a ter que desenvolver um lado mais humano, eu acho que a minha saída da terapia intensiva foi mais por uma necessidade de estar desenvolvendo um cuidado, uma aproximação maior com o cliente. Até a minha formação eu entendia que cliente bom era aquele que tinha um tubo na boca, que não falava, que estava ali inerte, e depois a vida foi agregando outros valores, outras experiências. Você começa a valorizar outras questões que são importantes na sua prática profissional, que fazem com que você amplie seu universo, o seu olhar em relação à profissão (EVMN13)

Eu tive época da minha vida que eu tinha tara por monitor, eu achava aquilo lindo, tinha fissura por CTI, sempre trabalhei em CTI esses anos todos. “_Ah, escolher? CTI! Estou em casa”. Sempre gostei muito, hoje já vejo a coisa de outra forma. Saí daquela máquina maravilhosa, mecanicista, para ver além do que o paciente tem. Há alguns anos se me perguntassem: "Ah o monitor? O monitor dá tudo para você, tudo e mais alguma coisa. Dá até troco." Hoje eu já penso diferente, porque o paciente não é só formado de corpo, ele tem uma mente. Mesmo ele totalmente monitorizado, você o perde de uma hora para outra.(EVFN17)

A aproximação entre a equipe de enfermagem e 0 cliente no CTI se dá na maioria das vezes para o cumprimento de atividades vinculadas à prescrição médica, ou referente aos cuidados com higiene corporal e medicação. Isto leva a um prejuízo na relação enfermeiro-cliente, a qual se torna coisificada. É necessário buscar unificar as dimensões objetivas e subjetivas presentes no processo de cuidado, o que se conforma como um desafio para a enfermagem que atua no ambiente tecnológico dos $\mathrm{CTI} .{ }^{10}$

0 avanço tecnológico trouxe como característica negativa a omissão dos elementos que se originavam da vida subjetiva do cliente, tornando-os cada vez mais irrelevantes na construção dos diagnósticos e desenvolvimento das terapias, em contraponto a uma imagem cada vez mais precisa da doença, através das evidências numéricas e gráficas. ${ }^{15}$ Reiterase que os enfermeiros precisam saber identificar em qual momento se deve dar maior peso às dimensões objetivas $e$ mensuráveis pelos produtos tecnológicos, e em que situação deve-se ampliar a valorização das experiências vividas pelos clientes. ${ }^{10}$

Uma questão que parece contribuir para a emergência da ação tecnológica é o desenvolvimento de uma dependência da tecnologia para o cuidado de determinadas clientelas. Neste caso, o enfermeiro não consegue se ver em um ambiente em que não haja tecnologia, bem como não vislumbra a possibilidade de cuidado sem o seu auxílio. Esta situação de dependência pode favorecer a condução das ações do enfermeiro orientadas apenas pelo saber tecnológico e pelas informações originadas do maquinário.

Não sei, eu lido há tanto tempo com equipamentos, que já faz parte da minha profissão, da minha vida, porque sempre trabalhei com isso, que às vezes assim, eu não percebo e eu não sei trabalhar com outra coisa, em outra área que não tenha essa parafernália toda. Eu estou acostumada o tempo todo com monitores a minha volta, com bombas infusoras, com respiradores, então isso já é tão comum na minha vida profissional, que eu não (pausa) não sei como trabalhar sem isso, já faz parte do meu ser, não sei com trabalhar sem esses equipamentos todos. (EVFD4)

Eu não me vejo em um setor, numa enfermaria, numa clínica aberta. Essa vivência de estar em um setor fechado, de ouvir os alarmes, apitos, já faz parte do meu dia-a-dia. Eu não saberia, hoje, trabalhar em um lugar sem esse aparato. Eu acho que é muito complicado, o enfermeiro ele tem que assistir sim o paciente, mas eu não consigo ver hoje um cuidado de enfermagem sem a tecnologia. Eu não consigo ver um cuidado de enfermagem em um paciente que não está monitorizado. (ENFD15)

Toda esta discussão serve de alerta para a importância dos profissionais desenvolverem uma prática de cuidar voltada para a singularidade do ser humano, ao invés de uma prática mecanicista. E aponta para a necessidade do enfermeiro que cuida colocar-se no lugar do outro, no intuito de entender suas dificuldades e necessidades. ${ }^{16}$

0 cuidar em enfermagem consiste em empreender esforços transpessoais de um ser para outro, no intento de proteger, promover e preservar a humanidade, auxiliando os sujeitos a encontrarem significados na doença, sofrimento, dor e até mesmo existenciais ${ }^{(11)}$. 


\section{CONSIDERAÇÕES FINAIS}

Conclui-se, então, que estas considerações expostas sinalizam para a possibilidade de existência de duas perspectivas/ linhas condutoras da ação do enfermeiro junto ao cliente que se utiliza dos aparatos tecnológicos, definidos aqui como cuidado tecnológico e ação tecnológica, os quais trazem implicações diretas na assistência de enfermagem prestada.

Numa destas linhas, parece existir uma fé cega na ciência e tecnologia. Como consequência, os indivíduos acreditam que a qualidade do tratamento depende da utilização de aparatos tecnológicos sofisticados, recém-lançados, o que se reflete em ações de cuidado que reproduzem essa lógica. Uma das explicações para esta tendência, em que a tecnologia tem status positivo, está amparada no sistema capitalista, 0 qual internaliza nos indivíduos, através da socialização e educação formal, o valor da tecnologia, uma vez que ela gera lucro e produtividade. Assim, o valor da tecnologia é estimulado por um "marketing" leigo e profissional. ${ }^{17}$.

Por outro lado, as representações que se constroem da tecnologia associando-a à gravidade do cliente e sua possível morte (proximidade com) implica uma ação que se diferencia no gradiente que, por conta destas representações, superlativa tal ação. Isto porque as representações se constroem para dar sentido à ação do sujeito, e, no caso em tela, o entendimento dos enfermeiros sobre a tecnologia conforma o cliente de tal modo que este passa a ser compreendido como em mais grave estado e mais próximo à morte. Levando-se em consideração que o cuidado prestado por este enfermeiro pode ser um determinante para a vida ou morte do cliente; consequentemente, 0 agir deste enfermeiro será composto de elementos que expressam este pensamento sobre a tecnologia, o que resultará no cuidado ao cliente. Um cuidado diferenciado pelo ambiente que o conforma.

0 modo como o cuidado irá se processar nestes cenários está na dependência das representações que os sujeitos elaboram sobre a tecnologia, a qual nesta pesquisa aponta para dois caminhos: se na representação não existir supremacia do saber tecnológico sobre os saberes inerentes ao cuidado de enfermagem, tem-se uma ação que articula os dois saberes levando ao cuidado tecnológico. Mas se, ao contrário, tivermos uma supremacia ou hierarquização do saber tecnológico, o agir do enfermeiro será orientado somente tendo em vista a máquina, na crença de que somente seu manuseio correto e as respostas que ela dá são suficientes. Neste caso, não se teria propriamente o cuidado tecnológico, mas uma ação tecnológica destituída dos elementos que constituem os saberes sobre o cuidado de enfermagem.

Os resultados apontam que tanto os novatos quanto os veteranos produzem discursos que veiculam elementos que contribuem para o entendimento do que se convencionou denominar nesta pesquisa de cuidado tecnológico e ação tecnológica. No que pese os limites desta pesquisa, não foi possível afirmar que cada grupo possui um modo de agir, por exemplo, os veteranos desenvolvem um cuidado tecnológico e os novatos, a ação tecnológica, ou vice-versa. 0 que se pode evidenciar é que ambos os modos coexistem no cuidado ao cliente no CTI.

Tomando como referência estas primeiras aproximações com a questão que se coloca, levantou-se o pressuposto de que a tecnologia (maquinário) inerente aos ambientes de terapia intensiva possa estar orientando a formação de determinados estilos de cuidar na enfermagem, sendo necessários novos estudos que invistam numa caracterização mais aprofundada das práticas de cuidado dos enfermeiros na terapia intensiva. Tal iniciativa pode trazer como contribuição o delineamento, a partir da caracterização dos estilos de cuidar, de uma clínica do cuidado de enfermagem que responda pela especificidade do cenário da terapia intensiva.

Reconhece-se, por fim, que o avanço tecnológico em saúde produziu uma mudança no modo como as pessoas passaram a entender e a agir diante das questões relativas ao cuidado em saúde. Contudo, para que o enfermeiro consiga prestar uma assistência que seja direcionada não somente pelas informações provenientes do aparato tecnológico, mas, também, fornecidas pelo sujeito partícipe do cuidado, aliando assim o aspecto humano e o tecnológico, ele precisa congregar habilidades do âmbito técnico e expressivo, para que atenda às necessidades determinadas pelas características relacionadas ao modo como se configura o cuidado nas unidades tecnológicas, ou seja, um cuidado tecnológico que possui como um dos agentes definidores a aproximação entre os elementos humano e tecnológico.

\section{NOTA}

aRecorte extraído da dissertação de Mestrado intitulada: "A tecnologia e o enfermeiro no ambiente da Terapia Intensiva: um encontro mediado pelas representações sociais", apresentada ao Programa de Pósgraduação em Enfermagem da Escola de Enfermagem Anna Nery Universidade Federal do Rio de Janeiro, 2008

\section{REFERÊNCIAS}

1- Silva RC, Ferreira MA. Representações sociais dos enfermeiros sobre a tecnologia no ambiente da terapia intensiva. Texto@ Contexto Enferm. $2009 \mathrm{jul} / \mathrm{set} ; 18(3)$ :489-97.

2. Oba MDV, Tavares MSG, Oliveira MHP. A morte mediante as representações sociais dos profissionais de saúde. Rev Bras Enferm. 2002; 55(1): 2630.

3. Benner P. From novice to expert: excellent and power in clinical nursing practice. California(USA): Addison Wesley; 1984. 
4. Jodelet D. Representações sociais: um domínio em expansão. In:. Jodelet D, organizadora. As representações sociais. Rio de Janeiro(RJ): EdUERJ; 2001p. 17-44.

5. Herzlich C. A problemática da representação social e sua utilidade no campo da doença. Physis. [on-line] 2005; [citado 2009 out. 30]; 15(supl): [aprox. 35 telas]. Disponível em http://www.scielo.br

6. Oliveira RS. A dialética do cuidado: o humano e o tecnológico em um Centro de Terapia Intensiva [dissertação]. Rio de Janeiro(RJ): Escola de Enfermagem Anna Nery, Universidade Federal do Rio de Janeiro; 2002.

7. Moscovici S. Representações sociais: investigações em psicologia social. Petrópolis (RJ): Vozes; 2003.

8. Silva RCL, Porto IS, Figueiredo NMA. Assistência de enfermagem e o discurso de humanização. Esc Anna Nery. 2008 jan/mar; 12 (1): 156 59.

9. Vargas MAO, Ramos FRS. Tecnobiomedicina: implicações naquilo e daquilo que a enfermagem faz em terapia intensiva. Texto@ Contexto Enferm. 2008 jan/mar; 17(1): 168-76.

10. BarbosaSFF. A transcendência do emaranhado tecnológico em cuidados intensivos: a (re)invenção possível. Blumenau (SC): Nova Letra; 1999.

11. Waldow VR. Atualização do cuidar. Aquichan. 2008; 8(1):85-96.

12. Hudak CM, Gallo BM. Cuidados intensivos de enfermagem: uma abordagem holística. 6ª ed. Rio de Janeiro(RJ): Guanabara Koogan; 1997.

13. Mendes PW, Castro ES, Ferreira MA. As vertentes do cuidado de enfermagem. Esc Anna Nery. 2003 maio/ago; 7(2): 239-46.

14. Menin MSS. Representação social e estereótipo: a zona muda das representações sociais.Psicologia: teoria e pesquisa. 2006 jan/abr; 22(1): 43-52.

15. Reiser SJ. The unfolding and ambiguities of survival therapy. Intern J Technol Assessm Health Care. 1992a; 8(3): 383-94.

16. Lucena AF, Crossetti MGO. Significado do cuidar na Unidade de Terapia Intensiva. Rev Gaucha Enferm. 2004; 25(2): 243-56.

17. Peixoto MRB. 0 uso da tecnologia no processo diagnósticoterapêutico: ótica do enfermeiro e do usuário. Rev Esc Enferm USP. 1994; (28)3: 53-62. 